\title{
SENTIMENTOS DA PESSOA EM HEMODIÁLISE: PERCEPÇÃO DA EQUIPE DE ENFERMAGEM
}

\section{FEELINGS OF A PERSON UNDER HEMODIALYSIS: PERCEPTION OF THE NURSING TEAM}

\section{SENTIMIENTOS DE LA PERSONA BAJO HEMODIÁLISIS: PERCEPCIÓN DEL EQUIPO DE ENFERMERÍA}

Anna Maria Oliveira Salimena ${ }^{1}$, Yule Caroline Nunes Costa ${ }^{2}$, Thaís Vasconcelos Amorim ${ }^{1}$, Rafael Carlos Macedo Souza ${ }^{3}$

\section{RESUMO}

Objetivo: Conhecer a percepção da equipe de enfermagem sobre os aspectos emocionais da pessoa em hemodiálise. Método: Pesquisa de natureza qualitativa com 22 participantes da Equipe de Enfermagem de uma clínica situada na Zona da Mata Mineira/MG que atende pessoas portadoras de Insuficiência Renal Crônica com terapêutica renal substitutiva, que nos meses de outubro e novembro de 2016 realizaram seus depoimentos por meio de entrevista aberta. Resultados: Da análise compreensiva emergiram as Unidades de Significação: Sentimentos negativos relacionados ao tratamento que interferem no convívio com os profissionais; Sentimentos positivos relacionados ao tratamento; e Ambiente familiar, vínculo e confiança entre a equipe de saúde e os pacientes. Evidenciou-se que a demanda de cuidados transcende as técnicas focadas apenas na doença existente. Conclusão: Considera-se que a compreensão da Equipe de Enfermagem sobre os sentimentos expressos tende a colaborar na qualidade de vida das pessoas em hemodiálise e na realização do tratamento humanizado focado na integralidade da assistência prestada pela Equipe de Enfermagem. Descritores: Insuficiência renal; Diálise renal; Cuidados de enfermagem.

\section{ABSTRACT}

Objective: To recognize the perception of the nursing team about the emotional aspects of an hemodialysis patient. Method: $A$ qualitative research with 22 participants of the Nursing Team of a clinic located in the Zona da Mata Mineira/MG, which serves patients with chronic renal insufficiency with renal replacement therapy who, in October and November 2016, performed their testimonies by means of an open interview. Results: From the comprehensive analysis emerged the Units of Significance: Negative feelings related to the treatment those interfere in the conviviality with the professionals; Positive feelings related to the treatment; Family environment, bonding and trust between the health team and patients. It showed that the demand for care transcends techniques that focus only on existing disease. Conclusion: It considers that the understanding of the Nursing Team about the expressed feelings tends to collaborate in the quality of people's life under hemodialysis and in the accomplishment of the humanized treatment focused on the integrality of the assistance provided by the Nursing Team.

Descriptors: Renal insufficiency; Renal dialysis; Nursing care.

\section{RESUMEN}

Objetivo: Conocer la percepción del equipo de enfermería acerca de los aspectos emocionales del paciente bajo hemodiálisis. Método: Investigación de naturaleza cualitativa con 22 participantes del Equipo de Enfermería de una clínica ubicada en la Zona de Mata Minera/MG, que atiende a pacientes portadores de Insuficiencia Renal Crónica con terapéutica renal sustitutiva que, en los meses de octubre y noviembre de 2016 realizaron sus testimonios por medio de una entrevista abierta. Resultados: Del análisis comprensivo surgieron las Unidades de Significación: Sentimientos negativos relacionados al tratamiento que interfieren en la convivencia con los profesionales; Sentimientos positivos relacionados al tratamiento; Ambiente familiar, vínculo y confianza entre el equipo y los pacientes. Se evidenció que la demanda de cuidados trasciende las técnicas enfocadas sólo en la enfermedad existente. Conclusión: Se considera que la comprensión del Equipo de Enfermería acerca de los sentimientos expresados tiende a colaborar en la calidad de vida de las personas bajo hemodiálisis y en la realización del tratamiento humanizado enfocado en la integralidad de la asistencia prestada por el Equipo de Enfermería.

Descriptores: Insuficiencia renal; Diálisis renal; Atención de Enfermería. 


\section{INTRODUÇÃO}

A Doença Renal Crônica (DRC) é considerada um grave problema de saúde pública, tratando-se de afecção de início assintomática e insidiosa, concorrendo para a perda da função renal por alterações heterogêneas que afetam tanto a estrutura quanto a função renal, com múltiplas causas e fatores de prognóstico ${ }^{(1)}$.

Sendo assim, a DRC é temida pela possibilidade de ocasionar a morte ou levar a complicações cardiovasculares, neurológicas e de perda total da função dos rins denominada Doença Renal Crônica Terminal (DRCT). Quando há a evolução para a DRCT, a pessoa necessita de algum tipo de Terapia Renal Substitutiva (TRS) como hemodiálise, diálise peritoneal e o transplante renal $^{(2)}$.

Dados da Sociedade Brasileira de Nefrologia (SBN) evidenciam que $70 \%$ das pessoas que fazem diálise descobrem a doença tardiamente. Além disso, a taxa de mortalidade é de $15 \%$ para quem enfrenta o tratamento. De acordo com o Censo Brasileiro de Diálise de 2014, o número estimado de usuários com DRC no Brasil, em tratamento dialítico, teve um grande aumento, passando de 42.695 em 2000 para 112.004 em $2014^{(3)}$.

A maior parte da população desconhece a gravidade da doença e, por ser muitas vezes uma doença silenciosa, incorre na ausência de prevenção e no descuidado com a própria saúde. Assim, as pessoas são diagnosticadas tardiamente ao surgir sintomas como edema nos tornozelos, dificuldades de concentração, diminuição do apetite e hematúria $^{(4)}$.

A pessoa portadora de Insuficiência Renal Crônica (IRC) submetida à hemodiálise é grave e demanda cuidados e tratamento especializado conduzido por profissionais de saúde com conhecimentos teóricos e práticos suficientes para realizarem assistência de qualidade e humanizada, além da sensibilidade que permita enxergar as necessidades psicossocioespirituais na perspectiva do respeito à individualidade e integralidade do ser cuidado.

Porquanto, no curso das sessões de hemodiálise, muitas sofrem com alterações fisiológicas como cansaço, mal-estar, queda de pressão arterial e câimbras; com desgaste emocional, o qual se traduz em sentimentos de tristeza, revolta, insegurança, frustração e preocupação com o futuro ${ }^{(5)}$.

Por todos estes apontamentos, ressalta-se a importância do cuidado de enfermagem singularizado. Ao atuar de modo mais constante e mais próximo aos portadores de DRC sob hemodiálise, a equipe de enfermagem deve buscar, por meio da escuta atentiva, conhecer e atender às demandas de cuidado na dimensão emocional, com vistas a contribuir para um melhor enfrentamento diário e para o aumento da qualidade de vida, prevenção de complicações e promoção da saúde, considerando o quadro clínico característico.

Neste sentido, tornou-se objetivo deste estudo conhecer a percepção da equipe de enfermagem sobre os aspectos emocionais da pessoa em hemodiálise.

\section{MÉTODOS}

Estudo exploratório de natureza qualitativa ${ }^{(6)}$. O cenário do estudo foi uma clínica situada na Zona da Mata Mineira que atende portadores de IRC com terapêutica renal substitutiva. Participaram 22 profissionais da Equipe de Enfermagem do Setor de Hemodiálise, atendendo aos critérios de inclusão: ser maior de 18 anos, atuar há pelo menos um ano na unidade, sem distinção de gênero, cor e religião e concordar em participar livremente, de forma voluntária, sem ônus; e de exclusão, os que estavam de licença ou de férias.

As informações foram obtidas por meio de entrevista aberta, nos meses de outubro e novembro de 2016, norteada pelas indagações: Que sentimento(s) você percebe na pessoa que está fazendo hemodiálise? Como você faz para enfrentar esse sentimento? Com a gravação em equipamento $\mathrm{Mp} 3$, objetivou-se total fidelidade aos depoimentos. O contexto da entrevista foi de uma conversa informal em encontro mediado pela empatia e redução de pressupostos com vistas a dar abertura à livre expressão. Os depoimentos foram transcritos na íntegra, respeitando as falas e, para manter o anonimato, foi assegurada a codificação de identificação com a letra $E$ de entrevistado e com números arábicos a sequência dos mesmos.

A análise compreensiva foi alcançada por meio de repetidas leituras atentivas a fim de identificar as estruturas essenciais, emergindo os significados expressos e a aproximações entre eles, o que possibilitou a construção das Unidades de Significação: Sentimentos negativos relacionados ao tratamento que interferem no convívio com os profissionais; Sentimentos positivos relacionados ao tratamento; e Ambiente familiar, vínculo e confiança entre a equipe de saúde e os pacientes.

Cumpriram-se as disposições da Resolução 466/12, do Conselho Nacional de Saúde (CNS), para pesquisa com seres humanos ${ }^{(7)}$. O projeto de pesquisa foi cadastrado na Plataforma Brasil CAAE 57834216.2.0000.5147 e analisado pelo Comitê de Ética em Pesquisa da Universidade Federal de Juiz de Fora, sendo deferido pelo Parecer de número 1.678.297.

\section{RESULTADOS E DISCUSSÃO}

Foram 22 depoentes, sendo três Enfermeiras e 19 Técnicos(as) de Enfermagem, 18 do sexo feminino e quatro do sexo masculino, com idade variando entre 20 a 56 anos e de 01 a 28 anos de trabalho no setor.

\section{Sentimentos negativos relacionados ao tratamento e que interferem no convívio com os profissionais}

Os depoentes observaram, nas pessoas em tratamento hemodialítico, tristeza, angústia, isolamento, medo, carência e consideraram o sofrimento como desencadeador ou aumento da depressão, desilusão e sentimento de perda da autonomia, suscitando nelas incapacidade de viver ou dificuldade de se viver com qualidade. Desde o início do tratamento, estão sempre ouvindo o que 
não podem fazer, o que, provavelmente, acarretam transtornos emocionais.

Também perceberam que devem compreender e entender as mudanças ocorridas na vida das pessoas, pois elas trazem consigo sentimentos de rancor, revolta, agressividade, violência e isolamento. Eventualmente, essas pessoas transferem tais sentimentos aos profissionais ou, ainda, sentem-se inconformadas com sua situação e não realizam o tratamento corretamente.

Estudos $^{(8)}$ apontam que esses sentimentos relatados como negativos são apresentados por frases, tom de voz, sorrisos ou lágrimas, evidenciando uma ambivalência entre alegria e revolta. Da mesma forma, esses fatores podem ser influenciados pelo entendimento que a pessoa possui em relação à doença, pelo impacto que ela ocasiona e pela dependência da máquina de hemodiálise $\mathrm{e}^{(9-10)}$, como destacado nestes recortes dos depoimentos:

[...] "Tem paciente que acha que a vida acabou, que vai morrer porque não pode comer e beber água. [...] (sentimentos) de rancor, e a gente tem que estar ali tentando dominar aquela situação" [...] (E1)

[...] “Eles são mais frágeis devido ao problema que enfrentam. Cada um tem um tipo de vida, uns enfrentam com mais tranquilidade, outros não, muitos entram em depressão" [...] (E2)

[...] "De início, eles ficam assim: ai meu Deus o que eu posso fazer, não vou poder fazer nada da vida. Uma mistura que eles têm de revolta" [...] (E3)

[...] "Qualquer coisa que aconteça com eles ficam muito tristes, muito aborrecidos, e a maioria das vezes eles passam mal por causa disso, porque guardam aquele sentimento dentro deles" [...] (E4)

[...] "Eles tentam esconder o sentimento de tristeza, tentam muito esconder da gente. E outros, bem revoltados, que a gente tem que estar dando um carinho maior, uma atenção, explicando" [...] (E7)

[...] "Eles não aceitam porque a vida tem muitas privações, então eles já ficam toda semana na máquina 4 horas. Aí, às vezes, quer viajar, não pode ficar sem a diálise [...] ficam tristes mesmo com essa situação" [...] (E8)

Percebe-se que a descoberta do tratamento se torna revoltante e a sensação de incapacidade faz com que as pessoas, inconscientemente, posicionem-se contra todos que estão ali para ajudá-los. Sentimentos negativos e comportamentos de revolta com o tratamento emergem como tortura e perda de tempo por não terem uma possibilidade de cura ${ }^{(8)}$.

Outro sentimento que os participantes relataram foi o de carência:

[...] "São muito carentes, sentem muita necessidade de alguém ouvindo." (E10)

[...] "Tem uns aqui que são muito carentes, às vezes fazem alguma coisa pra poder aparecer [...] vem aqui porque querem conversar com a gente" [...] (E11)

Essas mudanças no cotidiano da pessoa renal geram maior impacto no modo de vida, ocasionando perturbações e dificuldades em seu dia a dia, posto que o mesmo passa a depender de uma máquina para sobreviver e a conviver rotineiramente num setor de hemodiálise ${ }^{(10)}$.

Os sentimentos negativos existem e são expressos durante o tratamento da hemodiálise, pois, além do medo do prognóstico e da incapacidade, há a dependência econômica e a alteração da autoimagem que ocasionam várias mudanças provenientes do tratamento, atingindo seus familiares, que tendem a modificar seu dia a dia para dar apoio ao familiar com insuficiência renal crônica ${ }^{(11)}$.

[...] "Com o passar do tempo, ele deprime, começa a ficar desanimado, não quer vir. Revolta porque viu que não vai melhorar, que não tem jeito" [...] (E14)

[...] "Porque às vezes eles abalam com a doença, com problemas em casa, com dificuldades em casa. Muda totalmente a vida, a alimentação, a vida social, eles têm muitas restrições. Muitos entram aqui desanimados, pensam até mesmo em desistir" [...] (E17)

[...] "A gente sabe de todos os sentimentos negativos da hemodiálise, a necessidade de estar aqui 3 vezes por semana, de conviver com o acesso vascular; às vezes, esse acesso implicar diretamente na vida social dela, deixando ela até dentro de casa, fora desse convívio social" [...] (E20)

Pesquisadores $^{(9)}$ destacam que, entre as pessoas com IRC, a depressão é frequente e se relaciona com o aumento da morbidade e mortalidade. Outros estudiosos ${ }^{(5)}$ expressam que emergem no tratamento hemodialítico sentimentos como desespero, insegurança, medo, os quais provocam prejuízos no seu convívio social e também danos físicos e emocionais. Além disso, o enfrentamento do tratamento, que é desconhecido e prolongado, torna esse momento difícil para a pessoa e seus familiares ${ }^{(12)}$. Dentre os depoimentos, destacam-se:

[...] "Sentimentos são variados, você vê sentimentos de negação. De dificuldade, de angústia, de não querer o tratamento" [...] (E20)

[...] "Alguns negam a doença e o tratamento, acham que não vão se curar. É tudo muito não pra ele, a partir de agora você é um renal crônico, então não pode beber água, não pode comer comida com muito sal" [...] (E22)

[...] "Percebo muito temor e muito medo. Medo do que vai acontecer, do futuro, da dependência dos familiares. Muitos falam que têm medo de se tornar um estorvo pra família[...]" (E22)

A partir destes depoimentos, verifica-se que esses sentimentos se entrelaçam, afetando a vida pessoal em torno das mudanças que ocorrem na vida que, assim, sofre com a adesão ao tratamento e com alterações nos hábitos alimentares, por exemplo, incluindo a necessidade de seguir uma dieta adequada e quase sempre rigorosa.

Assim, ao compreender o significado dos sentimentos que são apresentados pelos profissionais, percebe-se que estes se expressam com sentimentos de tristeza, momentos de depressão, de revolta, de angústia, de medo e a não aceitação, o que interfere em sua vida cotidiana e na de seus demais familiares ${ }^{(10)}$. 
Diante do exposto, observa-se que, nos momentos de revolta, a pessoa em hemodiálise tende a transferir sua insatisfação para a equipe de enfermagem e a ocasionar um desconforto, embora os profissionais não reajam negativamente por entenderem que esta forma de expressão se deve às dificuldades de adaptação ao tratamento.

\section{Sentimentos positivos relacionados ao tratamento}

Os depoentes significaram que alguns pacientes aceitam com mais tranquilidade a doença e o tratamento, pois entendem a hemodiálise como um sentido de vida mais prolongado e demonstram esse sentimento pelo olhar, carinho e amor com os profissionais.

[...] "Tem paciente que já sabe relevar muito e entendeu; já sabe dominar a situação, os dias, o horário e o que não pode comer." (E1)

[...] "Em geral, hoje em dia, os pacientes têm aceitação boa para o tratamento. Eles têm um sentimento próspero porque veem o futuro numa perspectiva de vida mais prolongada" [...] (E5)

[...] "Tem os pacientes que são bem agradáveis, eles têm um sentimento de carinho, fazem questão de lembrar o seu aniversário. Carinho muito grande pela gente, um sentimento bonito mesmo de amor e de gratidão" [...] (E16)

[...] "As pessoas acima dos 40 têm uma visão diferente depois que entendem o que realmente é a hemodiálise, aceitam melhor, se cuidam melhor em relação à alimentação, a ingerir o líquido principalmente, eles são restritos" [...] (E17)

[...] "A gente percebe perseverança, alegria por estar viva, gratidão. Ele conseguiu ver que a hemodiálise significa vida e não fim da vida" [...] (E21)

Neste contexto, apreende-se que, quando as pessoas que realizam hemodiálise conseguem vislumbrar o tratamento com maior aceitação ${ }^{(14)}$, compreendem a necessária adesão para o aumento da qualidade de vida e isto se torna motivo de satisfação para os profissionais, estimulando-os a retribuir a atenção, o carinho e o amor.

\section{Ambiente familiar, vínculo e confiança entre a equipe de saúde e os pacientes}

Há relatos sobre como um ambiente familiar e vínculo maior com o paciente renal transmitem confiança, segurança e melhora em sua qualidade de vida. A importância de se imprimir algo a mais traduz-se em sentimentos como gratidão e trazem sensação mais confortável por considerar os profissionais da enfermagem e a equipe como um membro da família deles, conforme observado:

[...] "A gente está ali para poder dar uma base para eles [...]. A gente é psicólogo, mãe, tudo aqui dentro." [...] (E1)

[...] "Você acaba criando um vínculo muito grande com eles, faz parte, você vê 3 vezes na semana. É outra família que você tem [...]. Eles se sentem seguros, confiança na gente" [...] (E2)

[...] "Aqui, a gente é família do paciente. Acaba que conhece o sentimento de cada um. Os pacientes têm muita confiança para se abrir. Às vezes não falam com um, mas falam com outro o que está acontecendo; graças a Deus, com isso, a gente consegue descobrir e tentar ajudar" [...] (E3)

[...] "É o mesmo sentimento como se eu também fizesse parte da família dela, de amor, de carinho. Eu consigo sentir isso pelo abraço, pelo agradecimento por eu estar fazendo uma coisa importante pela vida deles." [...] (E8)

[...] "Em uma situação de perda é muito complicado, porque o vínculo existe. Eu já vivi situações aqui de mesmo sentimento de perda como se fosse alguém muito importante da minha família. Chego a me emocionar" [...] (E13)

Este sentimento de família mostra sempre a qualidade de assistência que os profissionais de enfermagem estão prestando, não se restringindo ao pensamento de ligar e desligar a máquina e deixar sem uma atenção necessária. Colaborando, pesquisadores ${ }^{(15)}$ expressam que, na hemodiálise, a equipe de enfermagem tornase uma presença constante, o que representa um elemento de maior contato com o paciente e uma parte de suma importância enquanto educadores para saúde, responsáveis por transmitir segurança e apoio quando necessário.

Percebe-se que ter um familiar juntamente com o paciente é valoroso para o enfrentamento da doença pois, em muitos casos, ele busca na equipe de enfermagem o que não encontra em casa. Percebe-se então que a equipe de enfermagem "representa" uma família para esse, na medida em que demonstra sentimentos de gratidão e de confiança aos profissionais. Isso porque, de fato, é com eles com quem se estabelece o convívio durante boa parte da semana, aumentando esse vínculo e transformando essa atenção oferecida e repassada pelos profissionais como se fossem mesmo membros da família.

É de grande valia acrescentar uma assistência integral acolhedora no setor de hemodiálise e que, para tal, os profissionais de enfermagem devem prestar uma assistência com o conhecimento científico e permeado pela subjetividade humana, com ações como o acolhimento, a escuta, o toque, a relação interpessoal, estabelecendo-se o vínculo terapêutico entre paciente e os profissionais da equipe $^{(13)}$.

Sendo assim, compreende-se que os profissionais deste setor têm, em si, um aspecto de integralidade do cuidar, buscam de uma forma humanizada trazer, durante o tratamento hemodialítico, conforto, bem como estabelecer um relacionamento adequado com os familiares envolvidos $^{(16)}$. Observa-se o quanto o ouvir esse paciente traz para ele sentimentos positivos e uma melhora na qualidade do tratamento, bem como a importância de se colocar no lugar do outro.

\section{CONSIDERAÇÕES FINAIS}

A Equipe de Enfermagem relatou como percebe os sentimentos da pessoa em tratamento hemodialítico, sendo compreendido que é importante saber se colocar no lugar do outro, o acolher, o apoiar, o dar segurança, o conversar, o dar atenção e o saber ouvir. Dessa maneira, possibilitam-se não somente o desenvolvimento 
técnico, mas o cuidar humanizado fundamental para a qualidade e segurança da assistência com uma assistência integral.

Acredita-se que este estudo possa contribuir para o ensino, para pesquisa e para a prática clínica, no que se refere ao cuidado realizado pelos enfermeiros e pelos técnicos de enfermagem, no contexto dialítico. O foco do trabalho não se concentra apenas na técnica proposta, mas visa aos sentimentos e às emoções bem como oferece aspectos importantes para reflexão acerca do cotidiano da assistência em enfermagem. Faz-se referência, principalmente, às pessoas com dificuldades emocionais e psíquicas para a aceitação de um tratamento contínuo e prolongado, para os quais a demanda de cuidados transcende as técnicas focadas apenas na doença existente.

Salientamos, como limitação deste estudo, a sua realização numa só clínica de terapêutica renal substitutiva. Portanto, destacamos a necessidade do desenvolvimento de outras pesquisas em outros cenários, pois sabe-se que a doença renal crônica dialítica e seu respectivo tratamento configuram-se entre as doenças/terapêutica que geram maior impacto na qualidade de vida da pessoa.

\section{REFERÊNCIAS}

1. Ministério da Saúde (Brasil), Secretaria de Atenção à Saúde, Departamento de Atenção Especializada e Temática. Diretrizes clínicas para o cuidado ao paciente com Doença Renal Crônica DRC no Sistema Único de Saúde [Internet]. Brasília, DF; 2014 [citado em 2016 ago 21]. Disponível em: http://soneri.org.br/wp-

content/uploads/2014/03/diretriz-cl-nica-drcversao-final2.pdf

2. Ministério da Saúde (Brasil), Secretaria de Atenção à Saúde. Portaria no 389, de 13 de março de 2014. Define os critérios para a organização da linha de cuidado da Pessoa com Doença Renal Crônica (DRC) e institui incentivo financeiro de custeio destinado ao cuidado ambulatorial prédialítico [Internet]. Brasília, DF; 2014 [citado em 2016 ago 21]. Disponível em: http://www.saude.ba.gov.br/portalcib/images/arq uivos/Portarias/2014/0. 03.2014.pdf

3. Sociedade Brasileira de Nefrologia. Censo brasileiro de diálise [Internet]. São Paulo; 2013 [citado em 2016 ago 21]. Disponível em: http://arquivos.sbn.org.br/pdf/censo 2013-1405.pdf

4. Organização Pan-Americana da Saúde (OPAS). Dia mundial do rim 2015: saúde dos rins para todos. [citado em 2016 dez 15]. Disponível em: http://www.paho.org/bireme/index.php?id=277\%3 Adia-mundial-do-rim-2015-saude-renal-paratodos\&option=com content

5. Salimena AMO, Souza MO, Melo MCSC, Ferreira MR. Daily life of a woman undergoing hemodialysis. Fundam Care [Internet]. 2016 [citado em 2017 ago 15];8(3):4636-43. Disponível em: http://www.seer.unirio.br/index.php/cuidadofunda mental/article/view/3664/pdf 1
6. Minayo MCS. O desafio do conhecimento: pesquisa qualitativa em saúde. 12a ed. São Paulo: Hucitec; 2012.

7. Ministério da Saúde (Brasil), Conselho Nacional de Saúde. Resolução $n^{\circ} 466$, de 12 de dezembro de 2012. Diretrizes e normas regulamentadoras de pesquisas envolvendo seres humanos. Diário Oficial da União, Brasília, DF, 2013 jun 13, seção 1.

8. Rudnicki T. Doença renal crônica: vivência do paciente em tratamento de hemodiálise. Contextos Clínicos [Internet]. 2014 [citado em 2017 ago 15];7(1):105-16. Disponível em: http://revistas.unisinos.br/index.php/contextosclini cos/article/view/ctc.2014.71.10

9. Mayer BLD, Ubessi LD, Stumm EMF, Kirchner RM, Barbosa DA. Sentimentos de pessoas renais crônicos e interferências em atividades sociais. Rev Baiana Enferm [Internet]. 2013 [citado em 2017 ago 15];27(1):31-4. Disponível em: https://portalseer.ufba.br/index.php/enfermagem/ article/view/6908

10. Maciel CG, Ferraz RN, França VV, Frazão IS, Borba AKOT. Adesão ao tratamento hemodialítico: percepção dos pacientes renais crônicos. Cogitare Enferm [Internet] 2015. [citado em 2017 ago 15];20(3):540-7. Disponível em: http://revistas.ufpr.br/cogitare/article/view/41112

11. Silva AS, Silveira RS, Fernandes GFM, Lunardi VL, Backes VMS. Percepções e mudanças na qualidade de vida de pacientes submetidos à hemodiálise. Rev Bras Enferm [Internet]. 2011 [citado em 2017 ago 15];64(5):839-44. Disponível em:

http://www.scielo.br/scielo.php?script=sci arttext \&pid=S0034-71672011000500006

12. Ferreira LF, Agra B, Formiga IV. Experiências e sentimentos de pacientes em terapia hemodialítica. RSC online [Internet]. 2017 [citado em 2017 ago 15];6(1):39-56. Disponível em: http://www.ufcg.edu.br/revistasaudeeciencia/inde x.php/RSC-UFCG/article/view/463/289

13. Alves LO, Guedes CCP, Costa BG. As ações do enfermeiro ao paciente renal crônico: reflexão da assistência no foco da integralidade. J Res Fundam Care online [Internet]. 2016 [citado em 2017 ago 15];8(1):3907-21. Disponível em: http://www.seer.unirio.br/index.php/cuidadofunda mental/article/view/3945/pdf 1809

14. Ottaviani AC, Souza EN, Drago NC, Mendiondo MSZ, Pavarini SCl, Orlandi FS. Esperança e espiritualidade de pacientes renais crônicos em hemodiálise: estudo correlacional. Rev Latino-Am Enferm [Internet]. 2014 [citado em 2017 ago 15];22(2):248-54. Disponível em: http://www.scielo.br/pdf/rlae/v22n2/pt 01041169-rlae-22-02-00248.pdf

15.Santana SS, Fontenelle T, Magalhães LS. Assistência de enfermagem prestada aos pacientes em tratamento hemodialítico nas unidades de nefrologia. Rev Cient ITPAC [Internet]. 2013 [citado em 2017 ago 15];6(3):5. Disponível em: https://www.itpac.br/arquivos/Revista/63/5.pdf 16. Terra FS, Costa AMDD, Ribeiro CCS, Nogueira CS, Prado JP, Costa MD, et al. O portador de insuficiência renal crônica e sua dependência ao tratamento hemodialítico: compreensão 
fenomenológica. Rev Bras Clin Med [Internet]. 2010 [citado em 2017 ago 15];8(4):306-10. Disponível em: http://files.bvs.br/upload/S/16791010/2010/v8n4/a003.pdf

Nota: Recorte da Monografia do Curso de Graduação em Enfermagem da Faculdade de Enfermagem da Universidade Federal de Juiz de Fora, MG.

Recebido em: 23/10/2017

Aprovado em: 20/03/2018

\section{Endereço de correspondência:}

Anna Maria de Oliveira Salimena

Rua Marechal Cordeiro de Farias, 172

CEP: 36.081-330 - Juiz de Fora/MG - Brasil

E-mail: annasalimena@terra.com.br 